\title{
Une réévaluation de la methode d'incorporation de H14C03- pour mesurer la nitrification autotrophe et son application pour estimer des biomasses de bactéries nitrifiantes A reassessment of the $\mathrm{H}^{14} \mathrm{CO}_{3}$ - incorporation method for measuring autotrophic nitrification and its use to estimate the biomass of nitrifying bacteria
}

\author{
N. Brion et G. Billen
}

Volume 11, numéro 2, 1998

URI : https://id.erudit.org/iderudit/705308ar

DOI : https://doi.org/10.7202/705308ar

\section{Aller au sommaire du numéro}

\section{Éditeur(s)}

Université du Québec - INRS-Eau, Terre et Environnement (INRS-ETE)

\section{ISSN}

0992-7158 (imprimé)

1718-8598 (numérique)

\section{Découvrir la revue}

Citer cet article

Brion, N. \& Billen, G. (1998). Une réévaluation de la methode d'incorporation de H14C03- pour mesurer la nitrification autotrophe et son application pour estimer des biomasses de bactéries nitrifiantes. Revue des sciences de l'eau / Journal of Water Science, 11(2), 283-302. https://doi.org/10.7202/705308ar

\section{Résumé de l'article}

Le processus de nitrification joue un rôle essentiel dans le cycle de l'azote dans les milieux aquatiques naturels. La mesure de l'activité nitrifiante est une étape obligée pour bien comprendre et quantifier les flux d'azote dans ces milieux. Ce travail présente une réévaluation de la méthode de mesure de l'activité nitrifiante autotrophe par la méthode d'incorporation de bicarbonate marqué au 14C et son application pour estimer des biomasses de bactéries nitrifiantes. La validité générale de la méthode a été démontrée par des tests menés sur des inhibiteurs de nitrification qui ont montré que l'utilisation combinée de $\mathrm{N}$-serve $(5 \mathrm{ppm})$ et de chlorate $(10 \mathrm{mM})$ inhibait de manière complète et spécifique l'oxydation d'azote et l'incorporation de carbone des deux groupes de bactéries nitrifiantes. Un facteur de rendement (carbone incorporé par azote oxydé) de 0,1 mole $\mathrm{C} /$ mole $\mathrm{N}$ a également été déterminé sur des cultures pures de bactéries nitrosantes et nitratantes. Pour l'activité potentielle, en particulier, les conditions optimales pour la mesure d'activité nitrifiante ont également été établis: un $\mathrm{pH}$ entre 7 et 8, une température entre 20 et $30^{\circ} \mathrm{C}$, une concentration en ammonium d'au moins $1 \mathrm{mmol} / \mathrm{l}$ et en oxygène d'au moins $6 \mathrm{mg} / \mathrm{l}$. Une relation entre les mesures d'activité nitrifiante potentielle et la biomasse des bactéries nitrifiantes a été établie sur culture pure. Elle montre que dans les conditions de mesures de l'activité potentielle, 1 $\mu \mathrm{g} C$ de bactéries nitrifiantes oxyde $0,04 \mu \mathrm{mol} \mathrm{N} / \mathrm{h}$ 


\title{
Une réévaluation de la méthode d'incorporation de $\mathrm{H}^{14} \mathrm{CO}_{3}{ }^{-}$pour mesurer la nitrification autotrophe et son application pour estimer des biomasses de bactéries nitrifiantes
}

\author{
A reassessment of the $\mathrm{H}^{14} \mathrm{CO}_{3}{ }^{-}$incorporation method \\ for measuring autotrophic nitrification and its use \\ to estimate the biomass of nitrifying bacteria
}

\section{N. BRION $1^{*}$ et G. BILLEN ${ }^{2}$}

Reçu le 8 septembre 1997, accepté le 23 février 1998**.

\section{SUMMARY}

The nitrification process plays an important role in the nitrogen cycle of aquatic environments. Measurement of the activity of nitrifying bacteria is thus essential to understand and quantify the general nitrogen fluxes in those environments. This work presents a reassessment of the autotrophic nitrifying activity measurement by the ${ }^{14} \mathrm{C}$-bicarbonate incorporation method and its use to estimate the biomass of nitrifying bacteria. The general validity of the method was demonstrated by experiments with nitrification inhibitors showing that the use of a combination of $\mathrm{N}$-serve ( $5 \mathrm{mg} / \mathrm{L}$, final concentration) and chlorate (10 mmol/L, final concentration) inhibited immediately, completely and specifically the nitrogen oxidation and the carbon incorporation of nitrifying bacteria. A yield factor (incorporated C/oxidized $\mathrm{N}$ ) of $0.11 \mathrm{~mol} \mathrm{C} / \mathrm{mol} \mathrm{N}$ was established for pure cultures of nitrifying bacteria. For the measurements of potential nitrifying activities, the optimal growth conditions of nitrifying bacteria were determined on enrichment cultures: a pH between 7 and 8 , a temperature between 20 and $30^{\circ} \mathrm{C}$, an ammonium concentration over $1 \mathrm{mmol} / \mathrm{L}$, and an oxygen concentration over $6 \mathrm{mg} / \mathrm{L}$. A relationship between potential nitrifying activity measurements and nitrifying biomass was defined on pure cultures: we showed that $1 \mu \mathrm{g} C$ of nitrifying bacteria oxidized $0.04 \mu \mathrm{mol} \mathrm{N} / \mathrm{h}$.

Key-words: nitrifying activity, nitrifying biomass, 14C-bicarbonate incorporation. nitrification inhibitors, $N$-serve, chlorate.

1. Université Libre de Bruxelles, Groupe de Microbiologie des milieux aquatiques, CP 221, Campus Plaine, Boulevard du Triomphe, 1050 Bruxelles, Belgique.

2. Laboratoire de Géologie Appliqué, Université Paris 6, Place Jussieu 4, 75005 Paris, France.

* Correspondance.

Vrije Universiteit Brussel, Dienst Analytische Chemie (ANCH), Pleinlaan 2, 1050 Bruxelles, Belgique. e-mail : nnbrion@ulb.ac.be.

* Les commentaires seront reçus jusqu'au 31 décembre 1998. 


\section{RÉSUMÉ}

Le processus de nitrification joue un rôle essentiel dans le cycle de l'azote des milieux aquatiques naturels. La mesure de l'activité nitrifiante est une étape obligée pour bien comprendre et quantifier les flux d'azote dans ces milieux. Ce travail présente une réévaluation de la méthode de mesure de l'activité nitrifiante autotrophe par la méthode d'incorporation de bicarbonate marqué au ${ }^{14} \mathrm{C}$ et son application pour estimer des biomasses de bactéries nitrifiantes. La validité générale de la méthode a été démontrée par des tests menés sur des inhibiteurs de nitrification qui ont montré que l'utilisation combinée de $\mathbf{N}$ serve $(5 \mathrm{ppm})$ et de chlorate $(10 \mathrm{mM})$ inhibait de manière complète et spécifique l'oxydation d'azote et l'incorporation de carbone des deux groupes de bactéries nitrifiantes. Un facteur de rendement (carbone incorporé par azote oxydé) de 0,11 mole $\mathrm{C} / \mathrm{mole} \mathrm{N}$ a également été déterminé sur des cultures pures de bactéries nitrosantes et nitratantes. Pour l'activité potentielle, en particulier, les conditions optimales pour la mesure d'activité nitrifiante ont également été établies : un pH entre 7 et 8 , une température entre 20 et $30^{\circ} \mathrm{C}$, une concentration en ammonium d'au moins $1 \mathrm{mmol} / \mathrm{L}$ et en oxygène d'au moins $6 \mathrm{mg} / \mathrm{L}$. Une relation entre les mesures d'activité nitrifiante potentielle et la biomasse des bactéries nitrifiantes a été établie sur culture pure. Elle montre que dans les conditions de mesures de l'activité potentielle, $1 \mu \mathrm{g} \mathrm{C}$ de bactéries nitrifiantes oxyde $0,04 \mu \mathrm{mol} N / \mathrm{h}$.

Mots clés : activité nitrifiante, biomasse nitrifiante, incorporation de 14C-bicarbonate, inhibiteurs de nitrification, $N$-serve, chlorate.

\section{INTRODUCTION}

Le processus de nitrification autotrophe de l'ammonium en nitrate joue un rôle essentiel dans le cycle de l'azote dans les milieux aquatiques naturels. II permet d'une part la régénération des formes oxydées de l'azote et d'autre part, lorsqu'il est couplé à la dénitrification dans les sédiments, il favorise l'élimination d'azote du milieu (JENKINS \& KEMP, 1984 ; RYSGAARD et al., 1993 ; JENSEN et al., 1996 ; entre autres). Pour bien comprendre et quantifier les flux d'azote dans ces environnements, la mesure de l'activité nitrifiante (taux d'oxydation d'ammonium et/ou de nitrites) ainsi que le dénombrement de ces micro-organismes sont des étapes obligées.

Les premières méthodes mises au point pour mesurer l'activité des bactéries nitrifiantes sont des méthodes non isotopiques qui se basent sur l'utilisation d'inhibiteurs de nitrification (nitrosation et/ou nitratation). L'activité nitrifiante y est déterminée en comparant les variations de concentrations en ammonium et/ou en nitrites entre un échantillon témoin et un échantillon traité par l'inhibiteur. Les inhibiteurs de nitrosation les plus couramment utilisés à cet effet sont le $\mathrm{N}$-serve (=Nitrapyrine=2-chloro-6-trichlorométhyl pyridine) (POWELL \& PROSSER, 1986 ; HENRIKSEN et al., 1981 et HALL, 1984), l'allylthiourée (HALL, 1984 ; BIANCHI et al., 1994), l'acétylène (SLOTH et al., 1995; et CAFFREY \& MILLER, 1995), le méthylfluoride (CAFFREY \& MILLER, 1995 ; HYMAN et al., 1994 et MILLER et al., 1993), et le diméthyl éther (HYMAN et al., 1994 et MILLER et al., 1993). L'inhibiteur de nitratation le plus utilisé est le chlorate (BELSER \& MAYS, 1980 ; WISSMAR et al., 1985 ; et BIANCHI et al., 1994). Ce type de méthodes ne peut être appliqué que lorsque les inhibiteurs utilisés n'affectent pas les autres processus intervenant dans le cycle 
de l'azote et lorsque les activités nitrifiantes sont suffisamment importantes pour permettre la détection de variations de concentrations durant des temps d'incubation qui soient suffisamment courts.

Actuellement, les méthodes les plus utilisées pour mesurer l'activité des bactéries nitrifiantes des milieux aquatiques et des sédiments, font appels à des traceurs isotopiques. Les principaux isotopes utilisés sont le ${ }^{15} \mathrm{~N}$ et le ${ }^{14} \mathrm{C}$. Les méthodes utilisant le ${ }^{15} \mathrm{~N}$ sont des méthodes de mesure directe de l'activité nitrifiante qui consistent soit à suivre l'apparition de ${ }^{15} \mathrm{NO}_{2}{ }^{-}$et de ${ }^{15} \mathrm{NO}_{3}{ }^{-}$dans un échantillon enrichi en ${ }^{15} \mathrm{NH}_{4}{ }^{+}$(MIYAZAKI et al., 1973 ; OLSON, 1981b; ENOKSON, 1986 ; LIPSCHULTZ et al., 1986), soit à suivre la dilution isotopique (suite à la production de ${ }^{14} \mathrm{NO}_{3}{ }^{-}$) dans un échantillon initialement enrichi en ${ }^{15} \mathrm{NO}_{3}{ }^{-}$(KOIKE \& HATTORI, 1978 ; RYSGAARD et al, 1993 ; WARD et al., 1989 ; entre autres). La méthode consistant à ajouter du ${ }^{15} \mathrm{NH}_{4}{ }^{+}$à l'échantillon ne peut être utilisée que dans des milieux riches en ammonium de manière à ce que l'enrichissement ne provoque pas une activation de la nitrification. La méthode de dilution isotopique ne présente pas ce désavantage mais elle nécessite des temps d'incubation très longs en cas de faible activité. Ceci constitue un lourd handicap en cas d'utilisation en routine.

La méthode au bicarbonate marqué au ${ }^{14} \mathrm{C}$ radioactif est une mesure indirecte de l'activité nitrifiante qui se base sur la chémo-autotrophie des bactéries nitrifiantes. Le principe est le suivant : l'oxydation d'ammonium en nitrate permet aux bactéries nitrifiantes d'incorporer du bicarbonate pour la synthèse de leur biomasse. En mesurant à l'obscurité la différence d'incorporation de $\mathrm{H}^{14} \mathrm{CO}_{3}{ }^{-}$ dans deux échantillons, l'un non traité, l'autre traité par un inhibiteur spécifique de la nitrification chémo-autotrophique, un taux d'incorporation de $C$ peut être déterminé. $C €$ taux d'incorporation de $\mathrm{C}$ est proportionnel au taux d'oxydation d'azote, moyennant un facteur de rendement Cincorporé/Noxydé qui est considéré comme constant (BILLEN, 1976 ; SOMVILLE, 1978 ; HALL, 1982 ; OWENS, 1986 ; BEROUNSKY \& NIXON, 1993). Diverses critiques ont été faites à l'encontre de cette méthode notamment concernant le choix de l'inhibiteur et la constance du rendement d'oxydation de substrat (BELSER, 1984).

Le dénombrement d'organismes nitrifiants dans les milieux aquatiques est difficile et aucune technique ne semble vraiment satisfaisante. Les principales méthodes utilisées se basent sur des techniques classiques de mise en culture et sur des techniques de biologie moléculaire. La technique du "nombre le plus probable " (NPP) pour dénombrer les bactéries nitrifiantes est la plus répandue. Cependant il a été prouvé qu'elle sous-estime considérablement la population à cause d'une sélection due au milieu de croissance choisi, qui ne peut être universel (BELSER \& MAYS, 1982). Une autre technique utilisée consiste à le dénombrer des colonies sur une gélose riche en $\mathrm{CaCO}_{3}$, la croissance d'une colonie produisant une acidification locale de la gélose qui devient plus claire à cet endroit. Cette technique comporte les mêmes désavantages que la technique NPP, le milieu solide utilisé étant encore plus sélectif (FOSSET \& BIANCHI, 1995). La technique d'immunofluorescence a été utilisée pour la première fois par BELSER \& SCHMIDT (1978). Elle consiste à colorer les cellules de bactéries nitrifiantes par des anticorps fluorescents spécifiques. Cette méthode est très restrictive car elle nécessite une étape préalable d'isolation de toutes les souches à identifier et à dénombrer, ce qui n'est pas toujours possible. II existe d'autre part un très grand nombre de sérotypes différents. MONTUELLE et al. (1996) ont par exemple montré que malgré l'isolation de 6 sérotypes différents de Nitrobacter $s p$., les dénombre- 
ments par immunofluorescence restaient bien inférieurs aux dénombrements par NPP. Enfin, plus récemment, une technique basée sur l'utilisation de sonde nucléique a été mise au point (VOYTEK \& WARD, 1995). Après identification du gène codant pour un des enzymes intervenant dans l'activité de nitrification (l'ammonium mono-oxygénase par exemple), elle consiste à purifier l'ADN d'un échantillon et à amplifier le gène recherché par PCR. Cette méthode permet surtout une analyse qualitative d'un échantillon, l'analyse quantitative n'étant approchée que par son étalonnage avec une des autres techniques de dénombrement citées (DEGRANGE \& BARDIN, 1995).

Une bonne alternative à ces techniques de dénombrement consiste à mesurer l'activité des bactéries nitrifiantes dans des conditions optimales pour leur croissance. Cette activité potentielle est en effet directement proportionnelle à la biomasse active d'organismes nitrifiants (BELSER \& MAYS, 1982).

Ce travail présente des résultats montrant la validité de la méthode de mesure d'incorporation de $\mathrm{H}^{14} \mathrm{CO}_{3}{ }^{-}$et son utilisation pour la détermination de la biomasse nitrifiante.

La validité générale de la méthode dépendra du choix d'un inhibiteur de nitrification qui devra inhiber de manière efficace et spécifique, l'oxydation d'ammonium et de nitrite, et l'incorporation de bicarbonate par les bactéries nitrifiantes. Elle dépendra aussi de la détermination du facteur de rendement (Cincorporé/Noxydé) qui devra être constant dans les conditions expérimentales choisies. Pour l'activité potentielle, en particulier, les conditions optimales pour la mesure d'activité nitrifiante devront également être établies. L'effet du $\mathrm{pH}$, de la concentration en substrat (ammonium ou nitrite et oxygène), et de la température ont été étudiés in vitro sur des cultures d'enrichissement de bactéries nitrifiantes provenant de la partie amont (non saline) de l'estuaire de la Seine. La relation entre la mesure d'activité nitrifiante potentielle et la biomasse des bactéries nitrifiantes a également été établie.

\section{MÉTHODES}

\section{Cultures de bactéries}

\section{Cultures continues enrichies en bactéries nitrifiantes}

Deux cultures continues ont été initiées par l'introduction d'eau provenant de l'estuaire de la Seine dans un réacteur à culture aéré et mélangé. L'une est alimentée par une solution nutritive minérale contenant de l'ammonium (MATULEWICH et al., 1975) pour $1 \mathrm{~L}$ de milieu, $\mathrm{NaCl} 2 \mathrm{~g}, \mathrm{MgSO}_{4} .7 \mathrm{H}_{2} \mathrm{O} 0,05 \mathrm{~g}, \mathrm{~K}_{2} \mathrm{HPO}_{4}$ $0,5 \mathrm{~g}, \mathrm{NaHCO}_{3} 2 \mathrm{mg}, \mathrm{NH}_{4} \mathrm{Cl} 0,15 \mathrm{~g}, 20 \mathrm{~mL}$ de solution d'ions métalliques chélatés (CARLUCCI \& STRICKLAND, 1968) et de l'eau déminéralisée ; la solution est stérilisée en autoclave à $120^{\circ} \mathrm{C}$ ) pour obtenir un enrichissement en bactéries nitrosantes. L'autre est alimentée par une solution nutritive minérale contenant des nitrites (MATULEWICH et al., 1975) même composition que le milieu pour les bactéries nitrosantes mais le chlorure d'ammonium est remplacé par $42 \mathrm{mg}$ de $\mathrm{KNO}_{2}$ ) pour obtenir un enrichissement en bactéries nitratantes. Le temps de séjour imposé dans les réacteurs est d'environ $48 \mathrm{~h}$. 


\section{Culture pure de bactéries nitrifiantes}

Deux souches pures de bactéries nitrifiantes ont été acquises au "National Collections of Industrial and Marine Bacteria » (Aberdeen, Scotland) : Nitrosomonas europaea (NCIMB 11850) et Nitrobacter winogradskyi (NCIMB 11846). Elles ont été maintenues en culture dans le milieu stérile décrit ci-dessus.

\section{Culture continue de bactéries hétérotrophes mixtes exempte de bactéries nitrifiantes}

Un échantillon d'eau d'étang (étang du Rouge Cloître, forêt de Soignes, Bruxelles) a servi d'inoculum pour une culture continue de bactéries hétérotrophes. Le milieu d'alimentation se compose de $7 \mathrm{~g}$ d'extrait de levure pour $1 \mathrm{~L}$ d'eau minérale commerciale (Evian) et est stérilisé par autoclavage à $120^{\circ} \mathrm{C}$. Un temps de séjour de $2 \mathrm{~h}$, bien inférieur au temps de génération minimum des bactéries nitrifiantes, est imposé.

\section{Dosages des formes inorganiques dissoutes de l'azote}

L'ammonium est dosé par la méthode colorimétrique au bleu d'indophénol (SLAWYC \& MC ISAAC, 1972). Les nitrites sont dosés par la méthode colorimétrique à la sulfanilamide (V.F. EPA, 1979 selon JONES, 1984). Les nitrates sont réduits en nitrites par agitation sur un lit de cadmium en grain dans un milieu basique (Jones, 1984), les nitrites étant dosés par la méthode décrite ci-dessus.

\section{Mesure du nombre et de la biomasse de bactéries nitrifiantes en culture pure}

L'abondance et le biovolume des bactéries nitrifiantes en cultures pures sont estimés par comptage et mesure visuelle directe en microscopie à épifluorescence après coloration au DAPI (4'-6 diamino 2-phenylindole) (PORTER \& FEIG, 1980).

La biomasse est calculèe à partir des biovolumes en utilisant un facteur de conversion établi expérimentalement en mesurant la teneur en carbone organique particulaire dans un échantillon de culture pure de Nitrosomonas europaea de densité connue, concentré 1000 fois par centrifugation. Le facteur de conversion obtenu est de $(7,33 \pm 1,61) \times 10^{-8} \mu \mathrm{gC} /$ cellule et de $(29,68 \pm 9,50) 10^{-8}$ $\mu \mathrm{gC} / \mu \mathrm{m}^{3}$. Cette valeur peut être comparée au facteur de conversion largement utilisé en écologie microbienne, établi empiriquement par SIMON \& AZAM (1989). Selon ces auteurs, pour un biovolume de 0,1 à $0,2 \mu \mathrm{m}^{3}$, gamme des biovolumes mesurés sur les bactéries nitrifiantes, le facteur de conversion est de 23 à 17,5 $\times 10^{-8} \mu \mathrm{gC} / \mu \mathrm{m}^{3}$, ce qui est n'est pas loin de la valeur déterminée expérimentalement.

Le facteur déterminé pour Nitrosomonas europaea sera également appliqué arbitrairement aux cultures de Nitrobacter winogradskyi.

\section{Dosage du bicarbonate}

Dans les échantillons d'eau naturelle, la concentration en bicarbonate est déterminée par simple titration acide à l'HCl 0,02 M. Dans les échantillons de milieux de culture, du fait de la présence d'un tampon phosphate, la concentration en bicarbonate est déterminée par la méthode dite d'évolution: dans une enceinte fermée, l'échantillon est acidifié, chauffé et soumis à un bullage de $\mathrm{N}_{2}$ 
chassant le $\mathrm{CO}_{2}$ produit vers une solution d'hydroxyde de baryum, de concentration initiale connue. La différence de concentration du $\mathrm{BaOH}$ mesurée avant et après bullage permet de déduire la concentration en bicarbonate de l'échantillon analysé (RODIER, 1984).

\section{Mesure des taux d'incorporation de bicarbonate}

L'échantillon, de concentration en $\mathrm{HCO}_{3}{ }^{-}$connue, est marqué par une quantité connue de bicarbonate marqué au ${ }^{14} \mathrm{C}$ (Amersham). Il est alors incubé dans les conditions voulues. En fin d'incubation, l'échantillon est filtré en quintuplicats sur des membranes en acétate de cellulose d'une porosité de $0,2 \mu \mathrm{m}$ (Sartorius) à l'aide d'une rampe de filtration (Millipore). Les filtres sont rincés 2 à 3 fois avec de l'eau de distribution avant d'être introduits dans des fioles à scintillation. Afin d'éliminer le ${ }^{14} \mathrm{C}$ non associé à la biomasse, les filtres sont imbibés de quelques gouttes de $\mathrm{HCl} 1 \mathrm{~N}$ et mis à sécher pour quelques heures sous une hotte aspirante. Les filtres sont dissous dans $10 \mathrm{~mL}$ de milieu scintillant, le mélange est agité à l'aide d'un vortex. II faut laisser le mélange se stabiliser durant 24 heures avant de compter la radioactivité par scintillation liquide.

Connaissant la concentration naturelle en bicarbonate de l'échantillon ( $\mathrm{Ci}$ en $\mu \mathrm{mol} / \mathrm{L}$ ), la radioactivité initiale ajoutée à l'échantillon (DPMi en $\mathrm{dpm} / \mathrm{L}$ ) et la radioactivité fixée par les bactéries dans l'échantillon (DPMfix en dpm/L) la quantité de carbone incorporé durant le temps d'incubation (Cinc en $\mu \mathrm{mol} / \mathrm{L}$ ) par les bactéries peut être calculé par la relation suivante $:$ Cinc $=(D P M f i x / D P M i) \times C i$.

\section{RÉSULTATS}

\section{Efficacité et spécifité des inhibiteurs de nitrification choisis}

Sur base des travaux réalisés par POWELL \& PROSSER (1986), HENRIKSEN et al. (1981), HALL (1984), BELSER \& MAYS (1980), WISSMAR et al. (1985), et BIANCHI et al. (1994) notre choix s'est porté sur deux inhibiteurs de nitrification: le NServe (connu comme un inhibiteur de la nitrosation) et le chlorate (connu comme un inhibiteur de la nitratation). Le $\mathrm{N}$-serve étant peu soluble dans l'eau, il doit être ajouté en solution dans de l'éthanol. Les deux inhibiteurs ont été testés quant à leur capacité à bloquer l'oxydation d'azote et l'incorporation de bicarbonate par les deux types de bactéries nitrifiantes. L'effet du solvant ethanol a également été considéré.

Une culture enrichie en bactéries nitratantes est marquée au $\mathrm{H}^{14} \mathrm{CO}_{3}{ }^{-}$et divisée en 5 sous-échantillons, dont un témoin, un deuxième traité à l'éthanol $(0,02 \%$ en concentration finale), un troisième traité au $\mathrm{N}$-Serve solubilisé dans l'éthanol ( $5 \mathrm{mg} / \mathrm{L}$ de $\mathrm{N}$-Serve et $0,02 \%$ en éthanol en concentration finale), un quatrième traité au chlorate (10 mmol/L en concentration finale) et un cinquième traité au N-Serve (solubilisé dans l'éthanol) et au chlorate (aux mêmes concentrations que précédemment) (figure 1). Ces échantillons sont incubés à l'obscurité pendant une trentaine d'heures. L'évolution de la concentration en nitrite dans l'échantillon témoin montre une vitesse constante de nitratation sur les $35 \mathrm{~h}$ de l'expérience, de $2,27 \mu \mathrm{mol} / \mathrm{L} / \mathrm{h}\left(r^{2}=0,99\right)$ avec une vitesse correspondante 

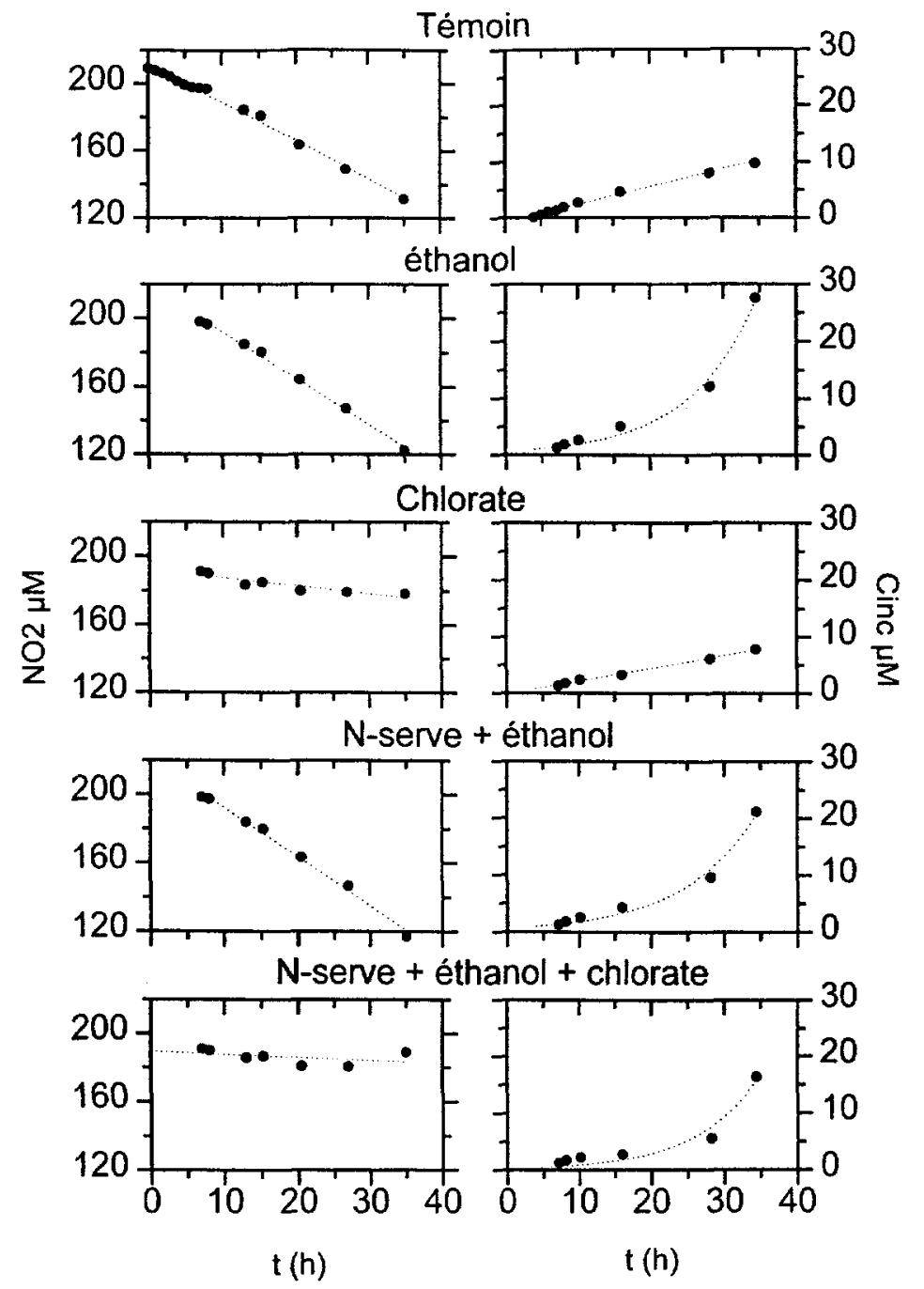

Figure 1 Évolution de la concentration en nitrite $\left(\mathrm{NO}_{2}\right)$ et du carbone incorporé (Cinc) dans un échantillon de culture enrichie en bactéries nitratantes avec et sans inhibiteurs de nitrification. Les vitesses d'oxydation d'azote (Noxy en $\mu \mathrm{mol} / \mathrm{L} / \mathrm{h}$ ) et d'incorporation de carbone (Cinc en $\mu \mathrm{mol} / \mathrm{L} / \mathrm{h}$ ) sont calculées par les pentes des régressions linéaires, $r^{2}$ entre parenthèses. Témoin : Noxy $=2,27(0,99)$, Cinc $=0,32(0,99)$; éthanol: Noxy $=2,7(0,99)$; chlorate: Noxy $=0,46(0,83)$, Cinc $=0,23(0,99) ; N$-serve+éthanol: Noxy $=2,9(0,99) ; N$-serve+éthanol+chlorate : Noxy $=0,17(0,2)$.

Nitrite concentration $\left(\mathrm{NO}_{2}\right.$ ) and carbon incorporation (Cinc) in a nitrite-oxidizing bacteria enrichment culture with and without nitrification inhibitors. $N$ oxidation (Noxy $\mu \mathrm{mol} / \mathrm{L} / \mathrm{h}$ ) and $C$ incorporation (Cinc $\mu \mathrm{mol} / \mathrm{L} / \mathrm{h}$ ) rates are calculated from the slopes of the linear regressions, $r^{2}$ value in brackets. Control (témoin) : Noxy $=2.27$ (0.99), Cinc $=0.32$ (0.99); ethanol: Noxy $=2.7$ (0.99); chlorate: Noxy $=0.46(0.83)$, Cinc $=0.23(0.99) ; N$-serve+ethanol: Noxy $=2.9(0.99) ; N$-serve+ethanol+chlorate $:$ Noxy $=0.17(0.2)$. 
d'incorporation de $\mathrm{HCO}_{3}{ }^{-}$de $0,318 \mu \mathrm{mol} / \mathrm{L} / \mathrm{h}\left(\mathrm{r}^{2}=0,99\right)$. Lajout d'éthanol ou d'éthanol $+\mathrm{N}-$ Serve n'ont pas d'effet significatif sur la vitesse d'oxydation des nitrites $\left(2,7\right.$ et $2,9 \mu \mathrm{mol} / \mathrm{L} / \mathrm{h}$ respectivement, $\left.\mathrm{r}^{2}=0,99\right)$ mais activent après une quinzaine d'heures l'incorporation de bicarbonate. Les chlorates inhibent la nitratation à $80 \%$ (vitesse d'oxydation des nitrites de $0,46 \mu \mathrm{mol} / \mathrm{L} / \mathrm{h}, \mathrm{r}^{2}=0,83$ ) ; l'incorporation de bicarbonate $\left(0,23 \mu \mathrm{mol} / \mathrm{L} / \mathrm{h}, \mathrm{r}^{2}=0,99\right)$ est également inhibée de $30 \%$
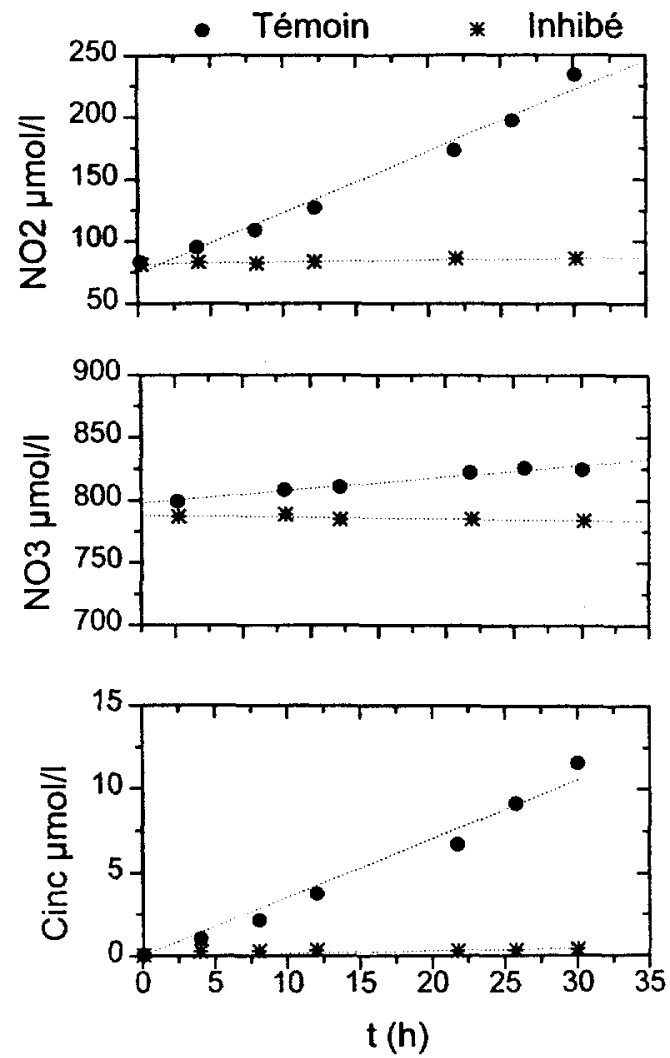

Figure 2 Évolution de la concentration en nitrite $\left(\mathrm{NO}_{2}\right)$, en nitrate $\left(\mathrm{NO}_{3}\right)$ et du carbone incorporé (Cinc) dans un échantillon de culture enrichie en bactéries nitrosantes avec et sans inhibiteurs de nitrification. Les vitesses d'oxydation d'azote (Noxy en $\mu \mathrm{mol} / \mathrm{L} / \mathrm{h}$ ) et d'incorporation de carbone (Cinc en $\mu \mathrm{mol} / \mathrm{L} / \mathrm{h}$ ) sont calculées par les pentes des régressions linéaires, ridem entre parenthèses. $\mathrm{NO}_{2}$ : Noxy témoin $=4,91(0,99)$, Noxy inhibé $=0,16(0,93) ; \mathrm{NO}_{3}$ : Noxy témoin $=0,93(0,96)$, Noxy inhibé $=-0,11(0,53) ;$ Cinc témoin $=0,35$ $(0,97)$; Cinc inhibé $=0,015(0,003)$.

Nitrite $\left(\mathrm{NO}_{2}\right)$ and nitrate $\left(\mathrm{NO}_{3}\right)$ concentrations, and carbon incorporation (Cinc) in an ammonium-oxidizing bacteria enrichment culture with and without nitrification inhibitors. $N$ oxidation (Noxy $\mu \mathrm{mol} / \mathrm{L} / \mathrm{h}$ ) and $\mathrm{C}$ incorporation (Cinc $\mu \mathrm{molh} / \mathrm{h}$ ) rates are calculated from the slopes of the linear regressions, ridem value in brackets. $\mathrm{NO}_{2}$ : Noxy control (témoin) $=4.91$ (0.99), Noxy inhibited $=0.16(0.93) ; \mathrm{NO}_{3}:$ Noxy control $=0.93(0.96)$, Noxy inhibited $=-0.11(0.53) ;$ Cinc control $=0.35(0.97) ;$ Cinc inhibited $=0.015$ (0.003). 
environ. La meilleure inhibition est obtenue par la combinaison de $\mathrm{N}$-serve et de chlorate (vitesse d'oxydation de nitrites de $0,17 \mu \mathrm{mol} / \mathrm{L} / \mathrm{h}, \mathrm{r}^{2}=0,18$ ), toutefois l'éthanol active ici aussi l'incorporation de carbone dans l'échantillon inhibé.

Une expérience semblable a été réalisée avec un échantillon de culture enrichie en bactéries nitrosantes. L'échantillon est marqué au $\mathrm{H}^{14} \mathrm{CO}_{3}{ }^{-}$et divisé en 2 sous-échantillons, dont l'un sert de témoin et l'autre, suite aux résultats obtenus précédemment, est traité au $\mathrm{N}$-serve (ajouté dans le flacon avant l'échantillon de manière à permettre l'évaporation du solvant éthanol) et au chlorate dans les concentrations précisées précédemment. Ces échantillons sont incubés à l'obscurité pendant une trentaine d'heures. L'évolution des nitrites et des nitrates (figure 2) dans l'échantillon témoin montre que la nitrosation se fait à une vitesse constante de $5,83 \mu \mathrm{mol} / \mathrm{L} / \mathrm{h}\left(r^{2}=0,99\right)$. Comme prévu dans cette culture enrichie en bactéries nitrosantes, la nitratation se fait à une vitesse réduite de $0,93 \mu \mathrm{mol} / \mathrm{L}\left(r^{2}=0,93\right)$. Lincorporation de bicarbonate dans l'échantillon témoin se fait également à une vitesse constante de $0,35 \mu \mathrm{mol} / \mathrm{L} / \mathrm{h}\left(\mathrm{r}^{2}=0,97\right)$. Lajout des inhibiteurs provoque immédiatement l'arrêt complet de la nitrosation et de la nitratation ce qui se traduit par une concentration en nitrites et en nitrates constantes au cours du temps. II provoque également l'arrêt quasi total (à $96 \%$ ) de l'incorporation de bicarbonate.

Enfin, dans la culture mixte de bactéries hétérotrophes, exempte de bactéries nitrifiantes, l'incorporation de $\mathrm{H}^{14} \mathrm{CO}_{3}{ }^{-}$a été mesurée en présence et en absence des inhibiteurs choisis (figure 3). Aucune différence significative n'est observée.

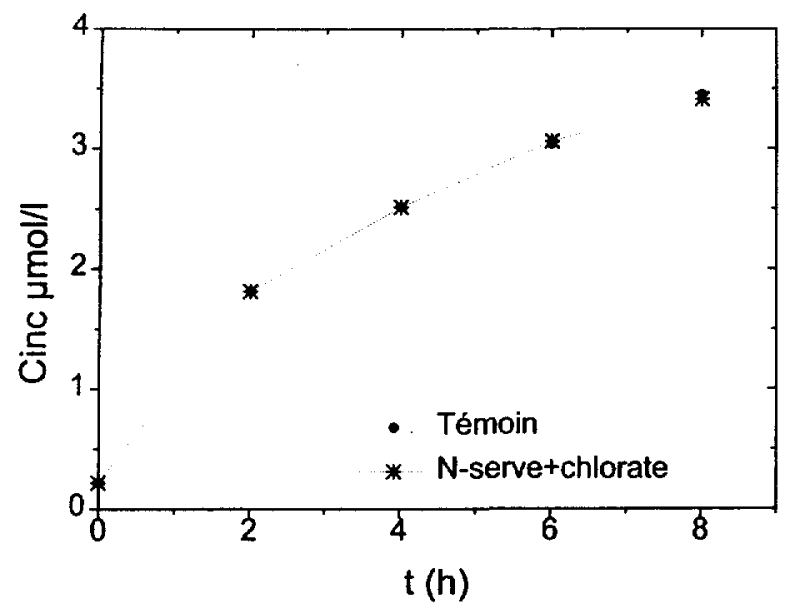

Figure 3 Évolution de l'incorporation de carbone (Cinc) dans une culture de bactéries hétérotrophes mixtes, avec et sans inhibiteurs de nitrification.

Carbon incorporation (Cinc) in a mixed heterotrophic bacteria enrichment culture with and without nitrification inhibitors.

\section{Effet de la température, du pH, de la concentration en ammonium ou en nitrite et de la concentration en oxygène sur les activités nitrifiantes}

Les mesures d'activité nitrifiante dans des cultures d'enrichissement réalisées en fonction de la température et $\mathrm{du} \mathrm{pH}$ se distribuent selon une courbe assimilable à une gaussienne (figures 4 et 5) ce qui permet de déterminer des tempéra- 

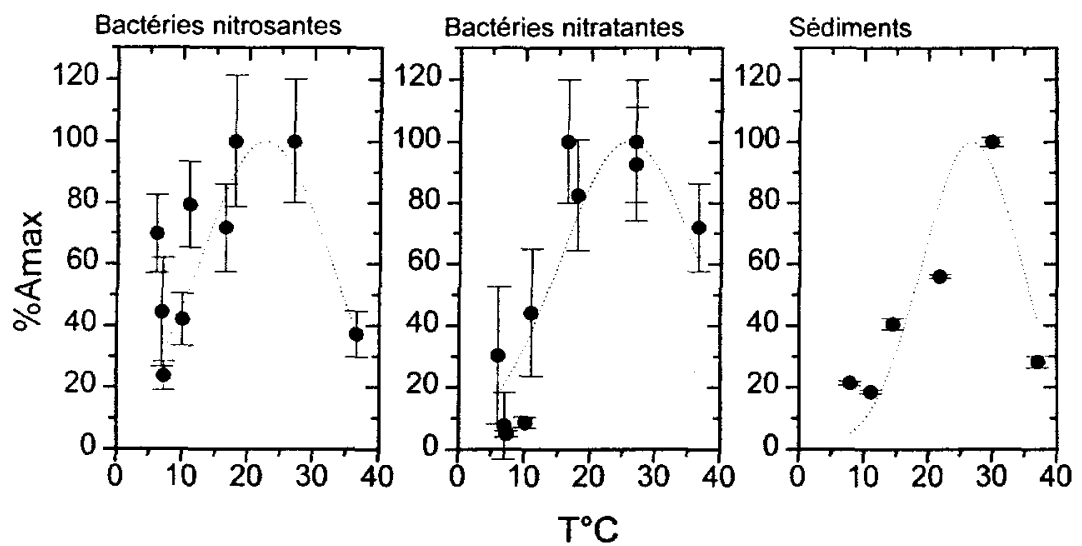

Figure $4 \quad$ Effet de la température (T) sur les mesures d'activité nitrifiante (AN) dans une culture enrichie en bactéries nitrosantes, une culture enrichie en bactéries nitratantes et un échantillon de sédiment lacustre. L'ajustement à une distribution gaussienne nous donne une température optimale \pm l'erreur standard de $22,6 \pm 0,8^{\circ} \mathrm{C}\left(r^{2}=0,5\right), 25,9 \pm 1,8^{\circ} \mathrm{C}\left(r^{2}=0,82\right)$, et $26,8 \pm$ $1,4^{\circ} \mathrm{C}\left(\mathrm{r}^{2}=0,75\right)$ pour les bactéries nitrosantes, nitratantes et les bactéries nitrifiantes des sédiments.

Effect of temperature ( $T$ ) on the nitritying activity (AN) of an ammonium- and a nitrite-oxidizing bacteria enrichment culture, and on a lake sediment sample. The fitting of a gaussian distribution gives an optimal temperature \pm the standard error of respectively $22.6 \pm 0.8^{\circ} \mathrm{C}\left(r^{2}=0.5\right), 25.9 \pm 1.8^{\circ} \mathrm{C}\left(r^{2}=0.82\right)$ and $26.8 \pm 1.4^{\circ} \mathrm{C}\left(r^{2}=0.75\right)$ for nitrite-, ammonium oxidizing bacteria, and sediment nitrifying bacteria.
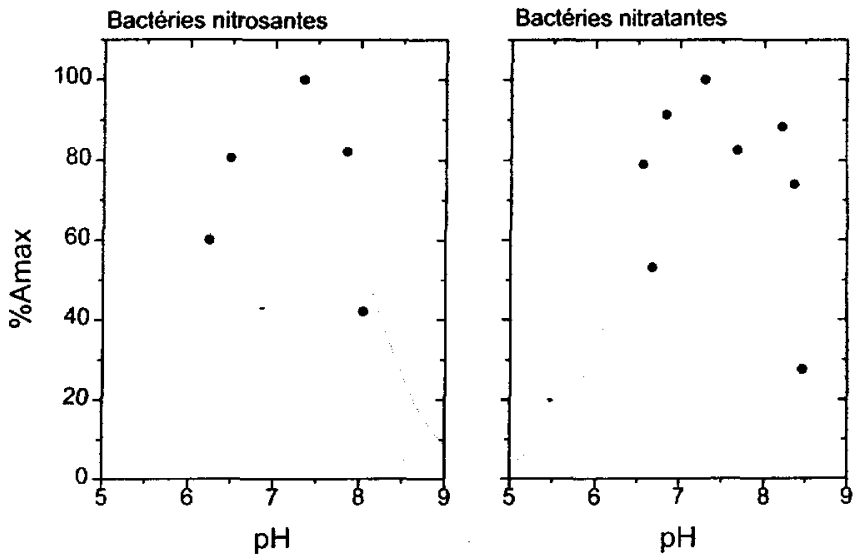

Figure 5 Effet du pH sur les mesures d'activité nitrifiante (AN) dans une culture enrichie en bactéries nitratantes et une culture enrichie en bactéries nitrosantes. L'ajustement à une distribution gaussienne nous donne un $\mathrm{pH}$ optimal \pm l'erreur standard de $7,1 \pm 0,1\left(r^{2}=0,82\right)$ et de $7,4 \pm 0,1\left(r^{2}=0,5\right)$ respectivement pour les bactéries nitrosantes et nitratantes.

Effect of $\mathrm{pH}$ on the nitrifying activity (AN) of a nitrite- and an ammonium-oxidizing bacteria enrichment culture. The fitting of a gaussian distribution gives an optimal $\mathrm{pH} \pm$ the standard error of respectively $7.1 \pm 0.1\left(r^{2}=0.82\right)$ and $7.4 \pm 0.1\left(r^{2}=0.5\right)$ for ammonium- and nitrite-oxidizing bacteria. 
tures et des $\mathrm{pH}$ optimaux pour les deux types de bactéries nitrifiantes. Pour les bactéries nitrifiantes des cultures enrichies il y a peu de différence entre les populations nitrosantes et nitratantes. Elles sont caractérisées par une température optimale de croissance de $25,9 \pm 1,8$ et $22,6 \pm 0,8^{\circ} \mathrm{C}$ (figure 4 ), et par un pH de $7,1 \pm 0,1$ et $7,4 \pm 0,1$ (figure 6 ) pour respectivement les bactéries nitrosantes et
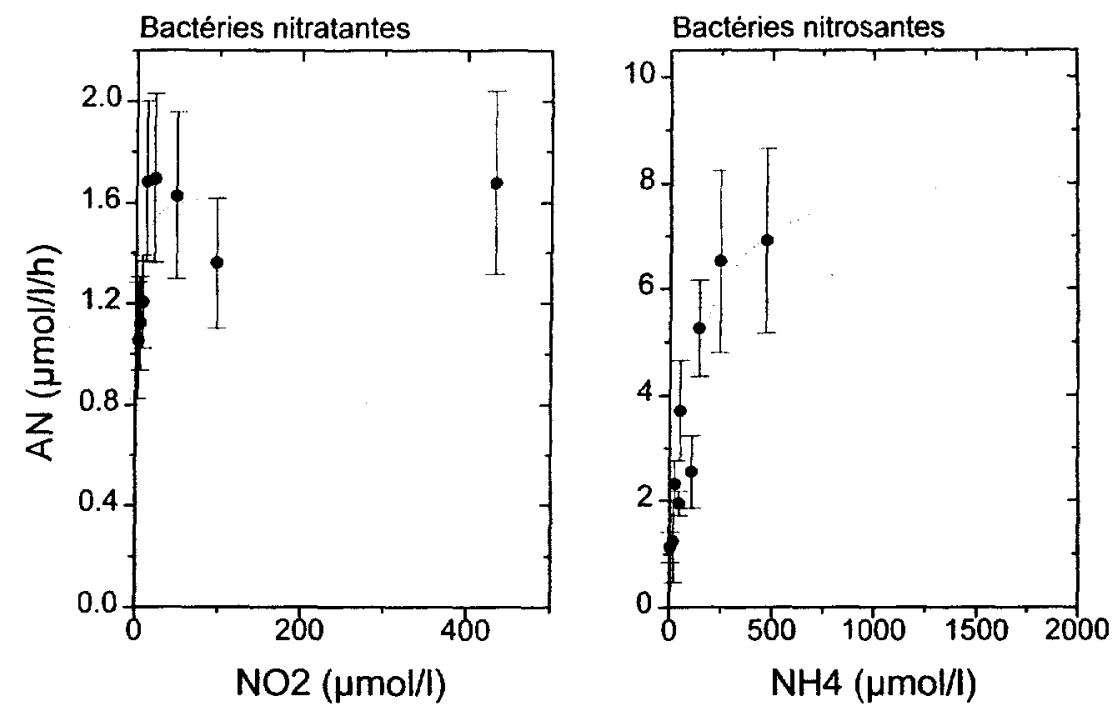

Figure 6 Effet de la concentration en substrat (ammonium, $\mathrm{NH}_{4}$ ou nitrite, $\mathrm{NO}_{2}$ ) sur les mesures d'activité nitrifiante (AN) dans une culture enrichie en bactéries nitratantes et une culture enrichie en bactéries nitrosantes. L'ajustement à une fonction de Michaelis-Menten donne respectivement une AN maximale l'erreur standard de $16,1 \pm 0,1$ et $8,6 \pm 1,5 \mathrm{mmol} / \mathrm{L} / \mathrm{h}$, avec un $\mathrm{Ks} \pm$ l'erreur standard de $1,7 \pm 0,7$ et $106,8 \pm 45,1 \mathrm{mmol} / \mathrm{L}$ pour les bactéries nitratantes et nitrosantes.

Effect of substrate concentration (ammonium, $\mathrm{NH}_{4}$ or nitrite, $\mathrm{NO}_{2}$ ) on the nitrifying activity (AN) of a nitrite- and an ammonium-oxidizing bacteria enrichment culture. The fitting to a Michaelis-Menten function gives respectively a maximum $A N \pm$ the standard error of $16.1 \pm 0.1$ and $8.6 \pm 1.5 \mathrm{mmol} / \mathrm{L} / \mathrm{h}$, with a Ks \pm the standard error of $1.7 \pm 0.7$ and $106.8 \pm 45.1 \mathrm{mmol} / \mathrm{L}$ for nitrite- and ammonium-oxidizing bacteria.

nitratantes. L'effet de la température a également été étudié sur un échantillon de sédiment lacustre (Lac du Der, France) (figure 4) : la température optimale trouvée est de $26,8 \pm 1,4^{\circ} \mathrm{C}$.

Classiquement, les mesures d'activité nitrifiante suivent une fonction de Michaelis-Menten avec la concentration en substrat (ammonium ou nitrite, et oxygène) (figures 6 et 7). Les constantes de demi-saturation pour les bactéries nitrosantes de nos cultures d'enrichissement sont de $107 \pm 45 \mu \mathrm{molNH}_{4}{ }^{+} / \mathrm{L}$, pour l'oxydation de l'ammonium et de $0,6 \pm 0,2 \mathrm{mgO}_{2} / \mathrm{L}$, pour l'utilisation d'oxygène. Pour les bactéries nitratantes de nos cultures d'enrichissement, les constantes de demi-saturation déterminées sont respectivement de $1,7 \pm 0,7 \mu \mathrm{molNO}_{2}{ }^{-} / \mathrm{L}$ et de $1,1 \pm 0,4 \mathrm{mgO}_{2} / \mathrm{L}$. 

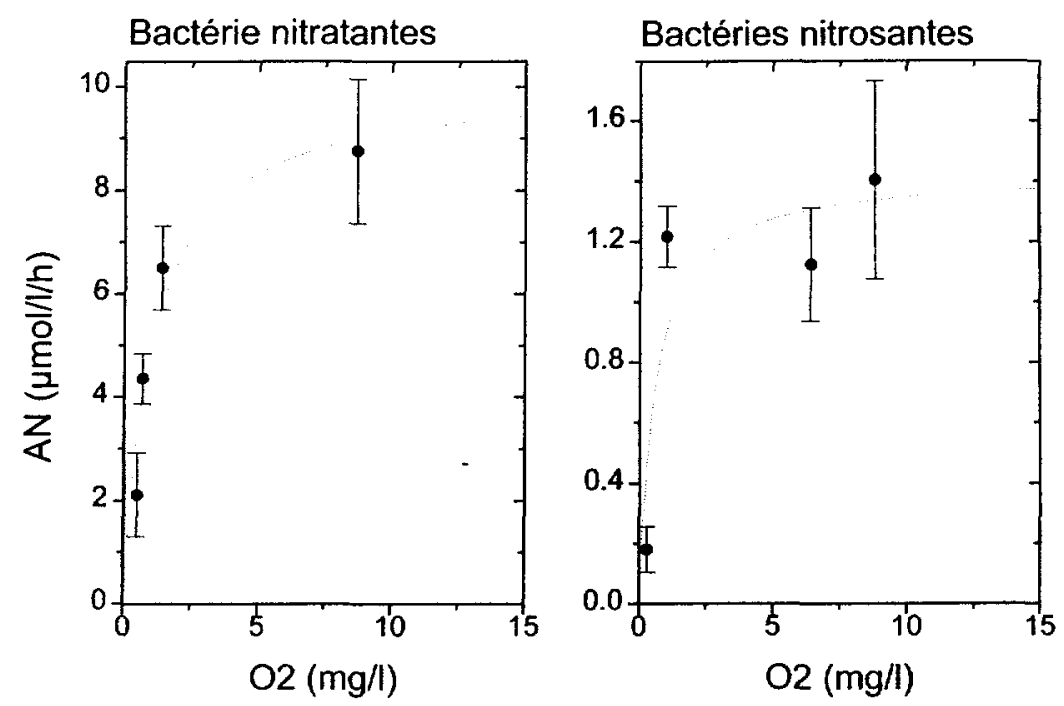

Figure 7 Effet de la concentration en oxygène $\left(\mathrm{O}_{2}\right)$ sur les mesures d'activité nitrifiante (AN) dans une culture enrichie en bactéries nitratantes et une culture enrichie en bactéries nitrosantes. L'ajustement à une fonction de MichaelisMenten donne respectivement une AN maximale \pm l'erreur standard de $10,5 \pm 1,8$ et $1,4 \pm 0,1 \mathrm{mmol} / \mathrm{L} / \mathrm{h}$, avec un $\mathrm{Ks} \pm$ l'erreur standard de $1,1 \pm 0,4$ et $0,6 \pm 0,2 \mathrm{mg} / \mathrm{L}$ pour les bactéries nitratantes et nitrosantes.

Effect of oxygen concentration $\left(\mathrm{O}_{2}\right)$ on the nitrifying activity (AN) of a nitriteand an ammonium-oxidizing bacteria enrichment culture. The fitting to a Michaelis-Menten function gives respectively a maximum $A N \pm$ the standard error of $10.5 \pm 1.8$ and $1.4 \pm 0.2 \mathrm{mmol} / \mathrm{h} / \mathrm{h}$, with a $\mathrm{Ks} \pm$ the standard error of $1.1 \pm 0.4$ and $0.6 \pm 0.2 \mathrm{mg} / \mathrm{L}$ for nitrite- and ammonium-oxidizing bacteria.

\section{Détermination du rendement d'utilisation de substrat, du taux de croissance maximum et de l'activité spécifique maximale des bactéries nitrifiantes}

Les paramètres caractéristiques de la croissance des bactéries nitrifiantes ont été déterminés expérimentalement en mesurant en parallèle dans une culture pure en croissance exponentielle l'évolution des concentrations en substrats $\left(\mathrm{NH}_{4}{ }^{+}\right.$et $\left.\mathrm{NO}_{2}{ }^{-}\right)$, la biomasse bactérienne évaluée par microscopie et l'incorporation de $\mathrm{H}^{14} \mathrm{CO}_{3}^{-}$, pendant une trentaine d'heures. Les résultats sont représentés dans la figure 8 .

Curieusement, le cumul de l'incorporation de bicarbonate radioactif fourni une courbe d'évolution de la biomasse supérieure à celle fournie par les estimations microscopiques. Ceci peut être lié à une mortalité qui accompagne la croissance cellulaire (les cellules mortes n'étant plus visibles au microscope alors que leur ${ }^{14} \mathrm{C}$ incorporé reste détectable), ou, plus probablement, à l'imprécision inhérente aux déterminations microscopiques de la biomasse.

Le rendement d'utilisation de substrat correspond à la quantité de biomasse produite par oxydation de substrat. Ce rendement peut être établi en portant les vitesses d'incorporation de carbone en fonction des vitesses d'oxydation de substrat, calculées d'après les pentes des courbes d'incorporation de carbone et 

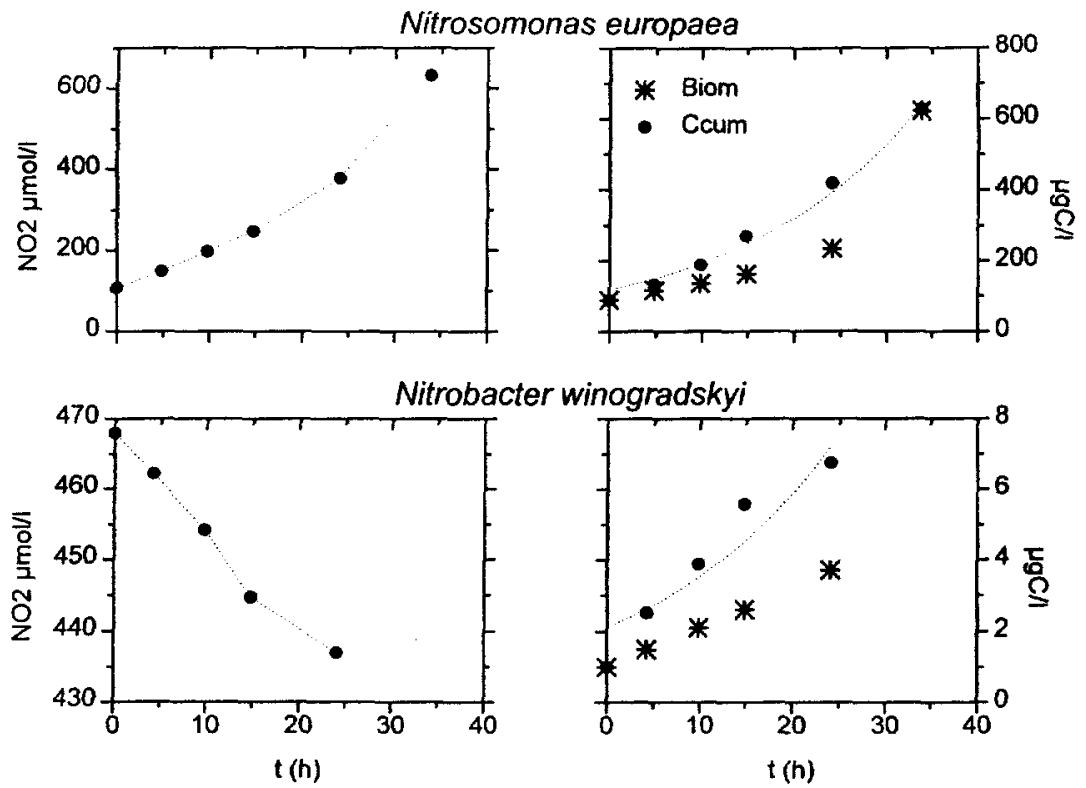

Figure 8 Évolution de la concentration en nitrite $\left(\mathrm{NO}_{2}\right)$, du carbone incorporé (Cinc), de la biomasse bactérienne (Biom) et du carbone incorporé cumulé (Ccum) dans une culture pure de Nitrosomonas europaea et de Nitrobacter winogradskyi en croissance optimale.

Nitrite concentration $\left(\mathrm{NO}_{2}\right.$ ), carbon incorporation (Cinc), bacterial biomass (Biom) and cumulated incorporated carbon (Ccum) in a pure culture of Nitrosomonas europaea and of Nitrobacter winogradskyi under optimal growth conditions.

d'oxydation d'azote (figure 9). Nous avons préféré cette méthode à celle qui se baserait sur les estimations microscopiques de biomasse, inévitablement entachées d'une imprécision beaucoup plus grande que la mesure de l'incorporation du carbone. Les valeurs ainsi trouvées du rapport carbone incorporé/azote oxydé sont de 0,09 $\pm 0,01 \mathrm{molC} / \mathrm{molN}$ pour Nitrosomonas europaea, et de 0,02 $\pm 0,001$ pour Nitrobacter winogradskyi.

Le taux de croissance maximum peut être obtenu en ajustant une courbe de croissance exponentielle aux points expérimentaux du carbone incorporé cumulé (figure 8). Un taux de croissance maximum à $30^{\circ} \mathrm{C}$ de $0,050 \pm, 003 \mathrm{~h}^{-1}$, pour les Nitrosomonas et de $0,051 \pm 0,013 \mathrm{~h}^{-1}$, pour les Nitrobacter, est ainsi obtenu.

L'activité spécifique maximale (ASmax) correspond à la vitesse maximale d'oxydation de substrat par biomasse bactérienne. Les valeurs d'activité spécifique maximale (ASmax) sont données par le rapport entre le taux de croissance optimal $\left(\mu \max , h^{-1}\right)$ et le rendement de croissance $(Y, \mu g C / \mu m o l N)$ : ASmax $=\mu \max / Y$. Les valeurs d'activité spécifique maximale sont donc de $0,05 \mu \mathrm{molN} / \mu \mathrm{gC} / \mathrm{h}$ pour les bactéries nitrosantes et de $0,21 \mu \mathrm{mo} / \mathrm{N} / \mu \mathrm{gC} / \mathrm{h}$ pour les bactéries nitratantes. 

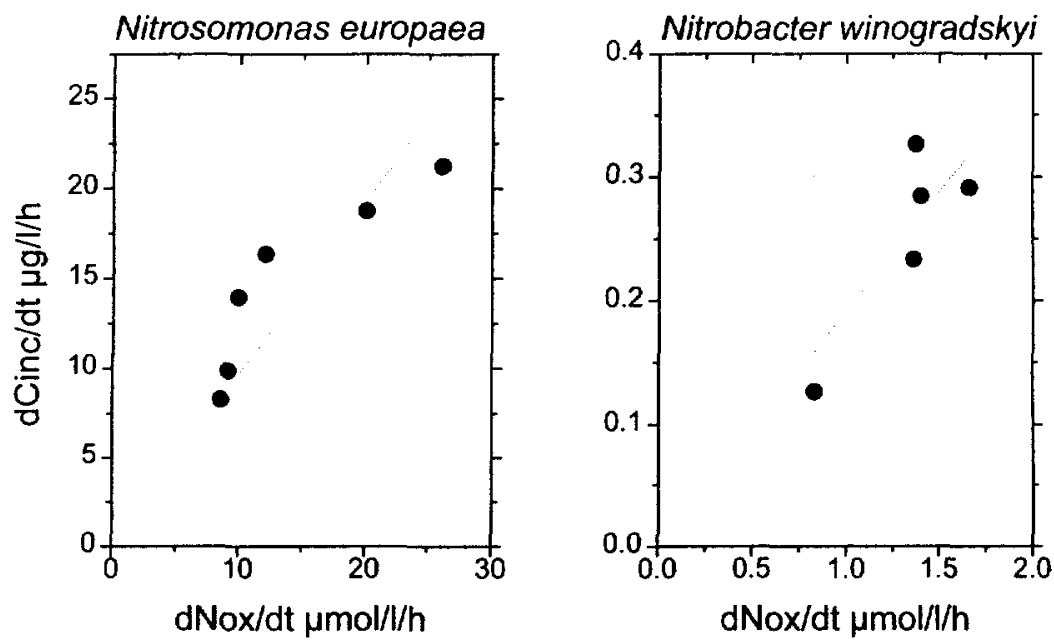

Figure 9 Taux d'incorporation de carbone (dCinc/dt) en fonction du taux d'oxydation d'azote ( $\mathrm{dN} / \mathrm{dt}$ ) et régression linéaire dans une culture pure de Nitrosomonas europaea et de Nitrobacter winogradskyi en croissance optimale. La pente des régressions donne un rendement d'utilisation de substrat de $0,09 \pm 0,01\left(r^{2}=0,55\right)$ et $0,02 \pm 0,001\left(r^{2}=0,72\right) \mathrm{mol} C / \mathrm{mol} N$ pour les bactéries nitrosantes et nitratantes respectivement.

Carbon incorporation rate (dCinc/dt) as a function of the nitrogen oxidation rate $(\mathrm{d} / \mathrm{N} / \mathrm{dt}$ ) and regression line in a pure culture of Nitrosomonas europaea and of Nitrobacter winogradskyi under optimal growth conditions. The slope of the regressions gives a yield of $0.09 \pm 0.01\left(r^{2}=0.55\right)$ and $0.02 \pm 0.001$ $\left(r^{2}=0.72\right)$ for ammonium- and nitrite-oxidizing bacteria respectively.

\section{DISCUSSION}

Validité générale de la méthode : inhibiteurs et rendement d'utilisation de substrat

Les résultats de nos expériences menées sur les inhibiteurs de nitrification montrent que la meilleure inhibition de l'oxydation d'ammonium et de nitrite est obtenue par l'utilisation combinée de $\mathrm{N}$-serve et de chlorate (figures 1 et 2).

En ce qui concerne l'inhibition de l'incorporation de bicarbonate : pour la culture de bactéries nitratantes l'ajout de chlorate provoque une inhibition de seulement $30 \%$ de l'incorporation de bicarbonate alors que l'oxydation de nitrite est inhibée à $80 \%$ (figure 1). Ceci indique qu'une part importante de l'incorporation de $\mathrm{C}$ est due aux bactéries hétérotrophes. En effet ces bactéries incorporent également du bicarbonate par voie anaplérotique. Elles sont en outre difficiles à éliminer d'une culture enrichie en bactéries nitrifiantes, à cause de leur temps de génération beaucoup plus court.

Au contraire, pour la culture de bactéries nitrosantes, l'ajout de $\mathrm{N}$-serve et de chlorate inhibe l'incorporation de C à $96 \%$ (figure 2). Dans ce cas, la contamination en bactéries hétérotrophes est beaucoup plus faible. 
Un problème indirect est cependant lié à l'utilisation du $\mathrm{N}$-serve comme l'un des inhibiteurs. En effet, l'expérience menée sur la culture de bactéries nitratantes montre que l'ajout d'éthanol (solvant du N-serve) résulte en une incorporation non linéaire de bicarbonate. Cette incoporation présente, en fait, une allure exponentielle (figure 1) ce qui masque l'effet inhibiteur du N-serve. Très probablement l'éthanol ajouté dans la culture en milieu minéral, représente un enrichissement en substrat carboné facilement utilisable par les bactéries hétérotrophes contaminantes, ce qui activerait leur incorporation de bicarbonate. Pour remédier à ce problème, le $\mathrm{N}$-serve devra être ajouté dans le flacon d'incubation avant d'ajouter l'échantillon afin de permettre l'évaporation complète du solvant éthanol. L'expérience réalisée sur la culture de bactéries nitrosantes montre que ceci n'enlève rien à l'efficacité du $\mathrm{N}$-serve, malgré sa faible solubilité dans le milieu aqueux (figure 2).

Ainsi, l'utilisation combinée de $\mathrm{N}$-serve et de chlorate permet d'obtenir une bonne inhibition de l'activité nitrosante et nitratante. Ils empêchent aussi l'incorporation de bicarbonate par les bactéries nitrifiantes sans affecter celle des bactéries hétérotrophes. Ils sont donc bien efficaces et spécifiques des bactéries nitrifiantes.

Tableau 1 Paramètres physiologiques des bactéries nitrosantes.

Table $1 \quad$ Physiological parameters of ammonium oxidizing bacteria.

\begin{tabular}{|c|c|c|c|}
\hline Paramètre & Unité & Auteurs (année 19..) & Valeur \\
\hline \multirow[t]{3}{*}{ Ks } & $\mu \mathrm{mol} / \mathrm{L}$ & Ce travail & 106,8 \\
\hline & & Loveless \& Painter (68) & 71 \\
\hline & & Cooper (83) & $60-170$ \\
\hline \multirow[t]{4}{*}{ Koxy } & $\mathrm{mg} / \mathrm{L}$ & Ce travail & 0,6 \\
\hline & & Schaberl \& Engel (64) & 0,5 \\
\hline & & Loveless \& Painter (68) & 0,3 \\
\hline & & Peeters et al. (69) & 0,2 \\
\hline \multirow[t]{3}{*}{ Topt } & ${ }^{\circ} \mathrm{C}$ & Ce travail & 22,6 \\
\hline & & Ce travail & 26,6 \\
\hline & & Helder \& De Vries (83) & $25-35$ \\
\hline \multirow[t]{2}{*}{ pHopt } & & Ce travail & 7,1 \\
\hline & & Loveless \& Painter (68) & $7,2-7,8^{-}$ \\
\hline \multirow[t]{6}{*}{$\bar{Y}$} & $\mathrm{molC} / \mathrm{molN}$ & Ce travail & 0,09 \\
\hline & & Gundersen (66) & $0,07-0,13$ \\
\hline & & Carlucci \& Strickland (68) & $0,06-0,1$ \\
\hline & & Belser (84) & $0,086-0,087$ \\
\hline & & Wezernak \& Gannon (67) & 0,09 \\
\hline & & Billen (75) & 0,088 \\
\hline \multirow[t]{3}{*}{$\mu \max$} & $n-1$ & Ce travail & 0,05 \\
\hline & & Skinner \& Walker (61) & 0,032 \\
\hline & & Helder \& De Vries (83) & 0,036 \\
\hline \multirow[t]{2}{*}{ ASmax } & $\mu \mathrm{molN} / \mu g \mathrm{C} / \mathrm{h}$ & Ce travail & 0,05 \\
\hline & & Belser \& Mays (82) & $0,055-0,314$ \\
\hline
\end{tabular}

Ks : constante de demi-saturation pour l'oxidation d'azote, Koxy : constante de demi-saturation pour l'utilisation d'oxygène, Topt : température optimale de croissance, $\mathrm{pHopt}$ : $\mathrm{pH}$ optimal de croissance, $Y$ : rendement de croissance, $\mu$ max : taux de croissance optimal, ASmax : activité spécifique maximale. 
Les rendements d'utilisation de substrats trouvés en culture pure sont tout à fait en accord avec les valeurs citées par divers auteurs (tableaux 1 et 2). En considérant que ce rendement est constant dans les conditions d'incubation des échantillons, il pourra être utilisé pour convertir les taux d'incorporation de $C$ par les bactéries nitrifiantes en taux d'oxydation d'azote.

Tableau 2 Paramètres physiologiques des bactéries nitratantes.

Table 2 Physiological parameters of nitrite-oxidizing bacteria.

\begin{tabular}{|c|c|c|c|}
\hline Paramètre & Unité & Auteurs (année 19..) & Valeur \\
\hline \multirow[t]{2}{*}{ Ks } & $\mu \mathrm{mol} / \mathrm{L}$ & Ce travail & 2 \\
\hline & & Olson (81a) & 0,07 \\
\hline \multirow[t]{4}{*}{ Koxy } & $m g / L$ & Ce travail & 1,1 \\
\hline & & Laudelout et al. (76) & 0,8 \\
\hline & & Loveless \& Painter (68) & 1 \\
\hline & & Peeters et al. (69) & $1,8-2,4$ \\
\hline \multirow[t]{3}{*}{ Topt } & ${ }^{\circ} \mathrm{C}$ & Ce travail & 25,9 \\
\hline & & Ce travail & 26,6 \\
\hline & & Helder \& De Vries (83) & $25-30$ \\
\hline \multirow[t]{2}{*}{ pHopt } & & Ce travail & 7,4 \\
\hline & & Boon \& Laudelout (62) & $7-8,6$ \\
\hline \multirow[t]{4}{*}{$\mathrm{Y}$} & $\mathrm{molC} / \mathrm{molN}$ & Ce travail & 0,02 \\
\hline & & Belser (84) & 0,024 \\
\hline & & Wezernak \& Gannon (67) & 0,0125 \\
\hline & & Schön (65) & $0,013-0,014$ \\
\hline \multirow[t]{5}{*}{$\mu \max$} & $h-1$ & Ce travail & 0,051 \\
\hline & & Gould \& Lees (60) & 0,058 \\
\hline & & Boon \& Laudelout (62) & 0,058 \\
\hline & & Knowles et al. (65) & 0,058 \\
\hline & & Helder \& De Vries (83) & 0,064 \\
\hline \multirow[t]{2}{*}{ ASmax } & $\mu \mathrm{molN} / \mu \mathrm{gC} / \mathrm{h}$ & Ce travail & 0,21 \\
\hline & & Eigeneer (75) & 0,445 \\
\hline
\end{tabular}

Ks : constante de demi-saturation pour l'oxidation d'azote, Koxy : constante de demi-saturation pour l'utilisation d'oxygène, Topt : température optimale de croissance, pHopt : $\mathrm{pH}$ optimal de croissance, $Y$ : rendernent de croissance, $\mu$ max : taux de croissance optimal, ASmax : activité spécifique maximale.

\section{Mesure d'activité potentielle et estimation de biomasse}

Les différentes valeurs déterminées pour les paramètres caractérisant la dépendance de l'activité nitrifiante à la température, au pH, à l'ammonium ou au nitrite et à l'oxygène, sont en bon accord avec celles citées par divers auteurs (tableaux 1 et 2). Ainsi, en admettant une marge de $10 \%$ sur l'activité maximale, les conditions optimales pour mesurer l'activité des bactéries nitrifiantes peuvent être définies : une température de 20 à $30^{\circ} \mathrm{C}$, un pH de 7 à 8 , une concentration en ammonium d'au moins $1 \mathrm{mM}$, et une concentration en oxygène d'au moins $6 \mathrm{mg} / \mathrm{L}$. En pratique les échantillons seront incubés à une température de $20^{\circ} \mathrm{C}$, en présence d'ammonium ( $2 \mathrm{mM}$ ) et sous agitation permanente (table agitante). Le $\mathrm{pH}$ des échantilions des milieux aquatiques naturels se trouve généralement dans la gamme optimale. 
La détermination d'une biomasse nitrifiante à partir de mesures d'activité nitrifiante potentielle est possible moyennant la détermination de l'activité spécifique maximale des bactéries nitrifiantes, correspondant au rapport entre le taux de croissance optimal et le rendement de croissance. Les valeurs mesurées dans cette étude du rendement de croissance, du taux de croissance optimal et de l'activité spécifique maximale sont du même ordre de grandeur que celles citées dans la littérature (tableaux 1 et 2).

\section{CONCLUSION}

Les résultats présentés ici permettent donc de valider l'usage de la méthode d'incorporation de bicarbonate radioactif en présence et en l'absence d'inhibiteurs pour mesurer l'activité nitrifiante en milieu aquatique. Par rapport aux protocoles originaux (BILLEN, 1975, SOMVILLE, 1978), nous proposons l'usage conjoint de deux inhibiteurs ( $\mathrm{N}$-serve et chlorate), et l'élimination par évaporation de l'éthanol pour éviter toute interférence avec les populations hétérotrophes.

La méthode peut être utilisée en conditions in situ, pour estimer l'activité nitrifiante réelle de l'échantillon. Dans ce cas, la mesure d'incorporation de bicarbonate peut être convertie en vitesse d'oxydation d'azote (en supposant l'équilibre des activités nitrosantes et nitratantes), en utilisant un facteur de conversion de $0,11 \pm 0,01 \mu$ moles de $C$ incorporé par $\mu$ mole d'azote oxydé $(0,09 \pm 0,01$ $\mu \mathrm{molC} / \mu \mathrm{molN}$ pour la nitrosation et $0,02 \pm 0,001 \mu \mathrm{molC} / \mu \mathrm{molN}$ pour la nitratation).

La méthode peut aussi être utilisée en plaçant l'échantillon en conditions optimales, quant à la température $\left(20-30^{\circ} \mathrm{C}\right)$, le $\mathrm{pH}(6,5-8)$, la teneur en oxygène $\left(>6 \mathrm{mgO}_{2} / \mathrm{L}\right.$ ) et la teneur en ammonium ( $>1 \mathrm{mmol} / \mathrm{L}$ ), de manière à réaliser une mesure de nitrification potentielle. Celle-ci peut être utilisée pour estimer une biomasse de bactéries nitrifiantes (toujours en supposant l'équilibre des populations nitrosantes et nitratantes) en considérant un facteur de conversion de $0,04 \mu \mathrm{molN} / \mathrm{h}$ par $\mu \mathrm{gC}$ bactérien $(0,05 \mu \mathrm{molN} / \mu \mathrm{gC} / \mathrm{h}$ pour les bactéries nitrosantes et $0,21 \mu \mathrm{molN} / \mu \mathrm{gC} / \mathrm{h}$ pour les bactéries nitratantes).

La rapidité de la méthode, sa sensibilité et le fait qu'elle ne nécessite pas d'équipement particulier, sinon celui nécessaire à la mesure du ${ }^{14} \mathrm{C}$, en fait une méthode très utile pour les travaux d'écologie aquatique.

\section{REMERCIEMENTS}

Ce travail a été financé par les programmes de recherche C.N.R.S. PIRENSeine (France) et Seine-Aval (France). Pour ce travail, Natacha Brion bénéficiait d'une bourse du FRIA (Belgique) dans le cadre d'un doctorat. 


\section{RÉFÉRENCES BIBLIOGRAPHIQUES}

BELSER L.W., SCHMIDT E.L., 1978. Physiology, biochemistry, and specific inhibitors of $\mathrm{CH}_{4}, \mathrm{NH}_{4}{ }^{+}$, and $\mathrm{CO}$ oxidation by methanotrophs and nitrifiers. Microbiol. Rev., 53, 68-84.

BELSER L.W., MAYS E.L., 1980. Specific inhibition of nitrite oxidation by chlorate and its use in assessing nitrification in soils and sediments. Appl. Environ. Microbiol., 39, 505-510.

BELSER L.W., MAYS E.L., 1982. Use of nitrifier activity measurements to estimate the efficiency of viable nitrifiers count in soils and sediments. Appl. Environ. Microbiol., $43,945-948$.

BELSER L.W., 1984. Bicarbonate uptake by nitrifiers: effects of growth rate, $\mathrm{pH}$, substrate concentration, and metabolic inhibitors. Appl. Environ. Microbiol., 48, 11001104.

BEROUNSKY V.M., NIXON S.W., 1993. Rates of nitrification along an estuarine gradient in Narraganset Bay. Estuaries, 16, 718730.

BIANCHI M., BONIN P., FELATRIA, 1994. Bacterial nitrification in the Rhône river plume (northwestern Mediterranean Sea). Mar. Ecol. Prog. Ser., 103, 197-202.

BILLEN G., 1975. Nitrification in the Scheldt estuary (Belgium and The Netherlands). Estuar. and coast. mar. Sci., 3, 79-89.

BILLEN G., 1976. Evaluation of nitrifying activity in sediments by dark ${ }^{14} \mathrm{C}$-bicarbonate incorporation. Wat. Res., 10, 51-57.

BOON B., LAUDELOUT H., 1962. Kinetics of nitrite oxidation by Nitrobacter winogradski. Biochem. J., 85, 440-477.

CAFFREY J.M., MILLER L.G., 1995. A comparison of two nitrification inhibitors used to measure nitrification rates in estuarine sediments. FEMS Microbiol. Ecol., 17, 213-220.

CARLUCCI A.F., STRICKLAND J.D.H., 1968. The isolation, purification and some kinetic studies of marine nitrifying bacteria. $J$. Exp. Mar. Biol. Ecol., 2, 156-166.

COOPER A.B., 1983. Population ecology of nitrifiers in a stream receiving geothermal inputs of ammonium. Appl. Environ. Microbiol., 45, 1170-1177.
DEGRANGE V., BARDIN R., 1995. Detection and counting of Nitrobacter populations in soil by PCR. Appl. Environ. Microbiol., 61, 2093-2098.

EIGENEER U., 1975. Adenine nucleotide pool variations in intact Nitrobacter winogradski cells. Arch. Microbiol., 102, 233 240.

ENOKSSON V., 1986. Nitrification Rates in the Baltic Sea: Comparison of three isotope techniques. Appl. Environ. Microbiol., 51, 244-250.

FOSSET C., BIANCHI M., 1995. Techniques de mesure des processus de nitrification en milieu marin. Oceanis, 21, 261-276.

GOULD G.W., LEES H., 1960. The isolation and culture of nitrifying organisms. Part 1. Nitrobacter. Can. J. Microbiol, 6, 299-307.

GUNDERSEN K., 1966. The growth and respiration of Nitrocystis oceanus at different partial pressures of oxygen. Can. $J$. Microbiol., 6, 299-307.

HALL G.H., 1982. Apparent and measured rates of nitrification in the hypolimnion of a mesotrophic lake. Appl. Environ. Microbiol., 43, 542-547.

HALL G.H., 1984. Measurement of nitrification rates in lake sediments: comparison of the nitrification inhibitors nitrapyrin and allythiourea. Microb. Ecol., 10, 25-36.

HELDER W., DE VRIES R.T.P., 1983. Estuarine nitrite maxima and nitrifying bacteria (Ems-Dollard estuary). Neth. J. Sea Res., 17, 1-18.

HENRIKSEN K., HANSEN J.I., BLACBURN T.H., 1981. Rates of nitrification, distribution of nitrifying bacteria and nitrate fluxes in different types of sediments from Danish waters. Mar. Biol., 61, 299-304.

HYMAN M.R., PAGE C.L., ARP D.J., 1994. Oxydation of methyl fluoride and dimethyl ether by ammonia monooxygenase in Nitrosomonas europaea. Appl. Environ. Microbiol., 60, 3033-3035.

JENKINS M.C., KEMP M., 1984. The coupling between nitrification and denitrification in two estuarine sediments. Limnol. Oceanogr., 29, 609-619.

JENSEN K.M., JENSEN M.H., KRISTENSEN E., 1996. Nitrification and denitrification in 
Wadden Sea sediments (Köningshafen, Island of Sylt, Germany) as measured by nitrogen isotope pairing and isotope dilution. Aquat. Microb. Ecol., 11, 181-191.

JONES M.N., 1984. Nitrate reduction by shaking with cadmium, alternative to cadmium columns. Wat. Res., 18, 643-646.

KNOWLES G., DOWNING A. L., BARRET M.J., 1965. Determination of kinetic constants for nitrifying bacteria in mixed culture with the aid of an electronic computer. $J$. Gen. Microbiol., 38, 263-278.

KOIKE I., HATTORI A., 1978. Simultaneous determination of nitrification and nitrate reduction in coastal sediments by a $15 \mathrm{~N}$ dilution technique. Appl. Environ. Microbiol., 35, 853-857.

LAUDELOUT H., LAMBERT R., PHAM M.L., 1976. The effect of $\mathrm{pH}$ and partial pressure of oxygen on nitrification. Ann. Microbiol., 127A, 367-382.

LIPSCHULTZ F., WOFSY S.C., FOX L.E., 1986. Nitrogen metabolism of the eutrophic Delaware River ecosystem. Limnol. Oceanogr., 31, 701-716.

LOVELESS J.E., PAINTER H.A., 1968. The influence of metal ions and $\mathrm{pH}$ on the growth of a Nitrosomonas strain isolated from activated sludge. J. Gen. Microbiol., $52,1-14$.

MATULEWICH V.A., STROM P.F., FINSTEIN M.S., 1975. Length of incubation for enumerating nitrifying bacteria present in various environments. Appl. Microbiol., $29,265-268$.

MILLER L.G., COUTLAKIS M.D., OREMLAND R.S., WARD B.B., 1993. Selective inhibition of ammonium oxidation and nitrification linked $\mathrm{N}_{2} \mathrm{O}$ formation by methyl fluoride and dimethyl ether. Appl. Environ. Microbiol., 59, 2457-2464.

MIYAZAKI T., WADA E., HATTORI A., 1973. Capacities of shallow waters of Sagami Bay for oxidation and reduction of inorganic nitrogen. Deep Sea Res., 20, 571-577.

MONTUELLE B., VOLAT B., TORIO-FERNANDEZ M., NAVARRO E., 1996. Changes in Nitrobacter serotypes biodiversity in a river: impact of a wastewater treatment plant discharge. Wat. Res., 30, 1057-1064.

OLSON R.J., 1981a. Differential photoinhibition of marine nitrifying bacteria : a possible mechanism for the formation of the pri- mary nitrite maximum. J. Mar. Res., 39, 227-238.

OLSON R.J., $1981 \mathrm{~b}$. ${ }^{15} \mathrm{~N}$ tracer studies of the primary nitrite maximum. J. Mar. Res., 39(2), 203-226.

OWENS N.J.P., 1986. Estuarine nitrification: a naturally occurring fluidized bed reaction? Estuar. coast. and Shelf Sci., 22, 3144.

PEETERS T.L., VAN GOAL A.D., LAUDELOUT, 1969. Kinetic study of oxygen limited respiration in nitrifying bacteria. Bact. Proc., 69, 141.

PORTER K.G., FEIG Y.S., 1980. Use of DAPI for identifying and counting of aquatic microflora. Limnol. Oceanogr., 25, 943948.

POWELL S.J., PROSSER J.1., 1986. Inhibition of ammonium oxidation by nitrapiryn in soil and liquid culture. Appl. Environ. Microbiol., 52, 782-787.

RODIEA J., 1984. L'analyse de l'eau, $7^{e}$ édition ; DUNOD, Paris.

RYSGAARD S., RISGAARD-PETERSEN N., NIELSEN L.P., REVSBECH N.P., 1993. Nitrification and denitrification in lake and estuarine sediments measured by the ${ }^{15} \mathrm{~N}$ dilution technique and isotope pairing. Appl. Environ. Microbiol., 59, 2093-2098.

SCHABERL P., ENGEL H., 1964. Dar verhalten der nitrification bakterien gegenuber geslotem. Arch. Fin. Mikrobiol., 393-400.

SCHÖN G., 1965. Untersushungen über der Nutzeffekt von Nitrobacter winogradskyi (Buch). Arch. Mikrobiol., 50, 111-132.

SIMON M., AZAM F., 1989. Protein content and protein synthesis rates of planktonic marine bacteria. Mar. Ecol. Prog. Ser., 5t, $201-213$

SKINNER F.A., WALKER N., 1961. Growth of Nitrosomonas europea in batch and continuous culture. Arch. Mikrobiol., 38, 339349.

SLAWYC G., MCISAAC J.J., 1972. Comparison of two automated ammonium methods in a region of coastal upwelling. Deep Sea Res., 4, 393-450.

SLOTH N.P., BLACKBURN H., HANSEN L.S., RISGAARD-PETERSEN N., LOMSTEIN B.AA., 1995. Nitrogen cycling in sediments with different organic loading. Mar. Ecol. Prog. Ser., 116, 163-170. 
SOMVILLE M., 1978. A method for the measurement of nitrification rates in water. Wat. Res., 12, 843-848.

VOYTEK M.A., WARD B.B., 1995. Detection of ammonium-oxidizing bacteria of the class Proteobacteria in aquatic samples with the PCR. Appl. Environ. Microbiol., 61, 1444-1450.

WARD B.B., KILPATRICK K.A., RENGER E.H., EPPLEY R.W., 1989. Biological nitrogen cycling in the nitracline. Limnol. Oceanogr., 34, 493-513.
WEZERNAK C.T., GANNON J.J., 1967. Oxygen nitrogen relationships in autotrophic nitrification. Appl. Mikrobiol., 15, 12111214.

WISSMAR R.C., LILLEY M.D., DE ANGELIS M., 1985. Nitrification and the inhibition of nitrite oxidation by chlorate in riverine surface sediments. Verh. Internat. Verein. Limnol., 22, 2749-2753. 